UDC 615.322:582.949.27

DOI: $10.15587 / 2519-4852.2021 .230290$

\title{
PHARMACOGNOSTIC ANALYSIS OF SALVIA HISPANICA L. SEEDS
}

\author{
Anastasiia Sutryn, Iryna Cholak, Oksana Yemelianova, Uliana Karpiuk
}

\begin{abstract}
The aim. The aim of this work was to conduct a microscopic and phytochemical study of the seeds of chia (Salvia his-
\end{abstract} panica $L$.).

Materials and methods. Chia seeds were examined macroscopically and microscopically. To study the qualitative composition of the main groups of biologically active substances, histochemical, microchemical and chemical reactions were used. Hydroxycinnamic acids were identified by paper chromatography. To obtain a lipophilic extract, a Soxhlet apparatus and an exhaustive chloroform extraction method were used. The study of the quantitative content of fatty acids was carried out by gas chromatography. The content of polysaccharides in the raw material was determined by the gravimetric method. According to the SPhU method, the raw material swelling index was determined.

Results. The main macro- and microscopic features of chia seeds have been established. Histochemical reactions, microchemical reactions made it possible to establish the presence of mucus and fatty oils in chia seeds. With the help of chemical reactions, the presence of flavonoids in the raw material was established. The quantitative content of fatty oils is $24.0 \pm 1.2 \%$. The content of water-soluble polysaccharides in the whole raw material was $4.01 \pm 0.07 \%$, in the crushed raw material $-5.04 \pm 0.05 \%$. As a result of determining the swelling index, it was found that this indicator for the whole chia seeds was 20, and for the crushed ones - 17. The content of hydroxycinnamic acids in the chia seeds was $1.07 \pm 0.03 \% .9$ fatty acids have been identified, among which linoleic acid predominates in terms of content.

Conclusions. The presence and quantitative content of mucus, fatty oils, water-soluble polysaccharides, flavonoids, hydroxycinnamic acids, fatty acids was confirmed in the seeds of chia (Salvia hispanica L.). The obtained data can be used to develop regulatory documentation for chia seeds in order to use this raw material in pharmacy and medicine

Keywords: Salvia hispanica L., seeds, histochemical analysis, phytochemical analysis, mucus, fatty oils, fatty acids, hydroxycinnamic acids, water-soluble polysaccharides, flavonoids

How to cite:

Sutryn, A., Cholak, I., Yemelianova, O., Karpiuk, U. (2021). Pharmacognostic analysis of Salvia Hispanica L. seeds. ScienceRise: Pharmaceutical Science, 2 (30), 49-54. doi: http://doi.org/10.15587/2519-4852.2021.230290

(C) The Author(s) 2021

This is an open access article under the Creative Commons CC BY license

\section{Introduction}

Modern dietary nutrition, natural products - the key to healthy longevity [1]. One of the reasons for interest in a healthy lifestyle is the increase in the number of people suffering from obesity, hypertension, diabetes and other comorbidities [2,3]. Of particular note is the seeds of chia (Salvia hispanica L.), which has become quite common in dietary [4] and preventive nutrition [5, 6]. In 2009, "The Official Journal of the European Union" published a permit to place chia seeds on the European market as a new food ingredient (Appendix 1) [7].

Numerous studies confirm the prospects for the use of chia seeds in medicine and pharmacy [1,3]. In Ukraine, there is currently no regulatory documentation for the pharmaceutical industry for chia seeds. Therefore, there is a need for phytochemical studies of this raw material for further use in the development of quality control methods.

Botanical affiliation of Spanish sage: kingdom Plants (Plantae), clade - Angiosperms (Magnoliophyta), class - Dicotyledons (Magnoliopsida), order - Lamiales, family - Lamiaceae, genus - Salvia L., species - Salvia hispanica L. Synonyms: Kiosmina hispanica (L.) Raf.;
S. chia Colla; S. prysmatica Cav.; S. schiedeana Stapf; Salvia tetragona Moench [8].

Salvia hispanica L. - source of dietary fiber, protein, fatty acids, carbohydrates [9, 10]. The content of dietary fiber in chia seeds is also quite significant - up to $40 \mathrm{~g}$ per $100 \mathrm{~g}$ [9]. Studies by foreign scientists indicate a significant effect of chia seeds in the correction of pathological conditions of cardiovascular diseases [11], kidney disease [12], obesity [13]. Some studies suggest that chia seeds have tonic and antioxidant activity [14, 15]. Currently, studies on the effectiveness of chia seeds in diabetes, obesity, cardiovascular disease $[15,16]$.

The presence of a wide range of biologically active substances (BAS) in chia seeds predicts their health benefits. In addition, the safety and efficacy of this medicinal plant raw materials (MPRM) must be confirmed by the results of appropriate experiments.

Data from literature sources and our previous studies confirm that the main active substances of chia seeds are mucus and fatty oils [17, 18]. But the most common foods on the Ukrainian market are yogurts and puddings, which are hydrophilic products. Therefore, there is a need to study flavonoids, polysaccharides, 
hydroxycinnamic acids of chia seeds, which can get into these products during production.

Given the above, our studies are devoted to the pharmacognostic study of chia seeds.

The aim of the research. The aim of the work was to conduct a microscopic study of chia seeds and phytochemical study of the composition of the main types of BAS of selected MPRM, as well as to create conditions for further use of the results in developing quality control methods for raw sage seeds.

\section{Research planning}

The analysis of scientific publications indicates that the chemical composition of S. hispanca seeds entering the Ukrainian market is insufficiently studied, which limits its use in medicine and pharmacy. This type of raw material requires the development of quality control methods, so it requires a more in-depth phytochemical study. It was decided to conduct an in-depth study of macro-, microscopic features of raw materials, and different classes of BAS that provide the pharmacological action of this plant. The study includes the following stages, shown in Fig. 1.

Carry out histochemical reactions to the main biologically active substance

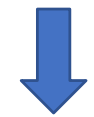

Carry out chemical reactions on different groups of BAS
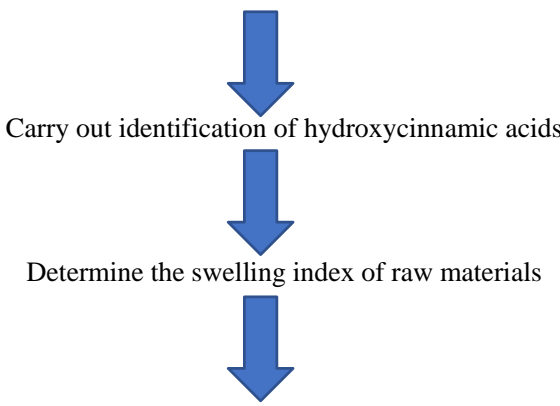

Establish the qualitative and quantitative content of fats and fatty acids

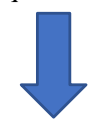

Determine the quantitative content of water-soluble polysaccharides

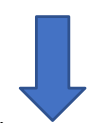

Determine the quantitative content of hydroxycinnamic acids

Fig. 1. Stages of sequential study of chia seeds

\section{Materials and methods}

The research was conducted on the basis of the Department of Pharmacognosy and Botany of the National Medical University named after O. O. Bogomolets (2019-2020). Samples of chia seeds, the main supplier of which to the Ukrainian market is Peru, were bought in Ukraine in food chain stores: seeds in paper bags, weight $0.5 \mathrm{~kg}$, production (packaging) - eco-farm "Zemledar", Ukraine, country of origin - Peru. Identification of MPRM was performed by macroscopic and microscopic methods [19].

Macroscopic analysis was performed with the naked eye and with a magnifying glass (magn. $1 \times 10)$ [20].
Microscopic analysis of seeds was performed using stereo and light microscopy [19]. The main diagnostic features of chia seeds from cross-sections, powder and whole seeds were studied. Seed preparations were first examined under a Leica S9i Stereozoom stereomicroscope at a magnification of 128 times on the basis of "ALT Ukraine Ltd.", in the department of microscopy and histopathology, as well as with a ULAB binocular light microscope at a magnification of 40, 100 and 400 times. Slices were photographed using a Canon EOS 550 SLR camera [20].

Histochemical reactions to mucus were performed according to the classical method with methylene blue, with mascara, with sodium hydroxide, with Sudano III, with Lugol's solution on whole raw materials (cross section) and powdered. The results of the reaction were examined with the naked eye and under a microscope [20].

Phytochemical analysis used chemical reactions to detect the following groups of BAS in aqueous and aqueous-alcoholic extracts with MPRM: tannins, saponins, flavonoids and alkaloids [21].

Identification of hydroxycinnamic acids was performed by paper chromatography (PC). For chromatographic analysis, $1.0 \mathrm{~g}$ of skimmed raw material was placed in a conical flask with a section, filled with $10 \mathrm{ml}$ of $70 \%$ ethyl alcohol, combined with a reflux condenser and heated in a water bath for 30 minutes The resulting extract was cooled and filtered through a paper filter. PC studies were performed on Filtrak chromatographic paper (FN-12, 14); samples of caffeic, chlorogenic and ferulic acids were used for comparison. Chromatographic study was performed in a system of $15 \%$ acetic acid solution (Merck, p.a.) After passing the front to the finish line, the plate was removed from the chamber, dried, determined spots of hydroxycinnamic acids in visible and UV light at a wavelength of $254 \mathrm{~nm}$ to and after treatment with ammonia vapor [22].

Soxhlet's apparatus and the method of exhaustive extraction with chloroform (Merck, p.a.) were used to obtain the lipophilic extract [23]. Determination of lipophilic content was performed for crushed raw materials. The study of the quantitative content of fatty acids was performed by gas chromatography (GC) on a chromatograph series "Color-500" in isothermal mode with a flame-ionizing detector under the following conditions: glass column (dimensions $3.0 \times 0.3 \mathrm{~cm}$ ), filled phase $5 \%$ polyethylene glycol succinate with a grain size of 0.125 $0.160 \mathrm{~mm}$, column temperature $-190{ }^{\circ} \mathrm{C}$, evaporator temperature $-250{ }^{\circ} \mathrm{C}$, nitrogen and hydrogen consumption - $35 \mathrm{ml} / \mathrm{min}$, air flow rate $-200 \mathrm{~mm} / \mathrm{min}$, chart speed $-240 \mathrm{~mm} / \mathrm{h}$, the sensitivity of the amplifier scale 10-7 A, the volume of the injected sample $-5 \mu \mathrm{l}$, the duration of the analysis - 20 minutes. To identify fatty acids, we compared the retention times of the peaks of methylated fatty acid derivatives and the standard mixture. The content of fatty acids was calculated as a percentage of their sum [24].

Quantitative determination of the amount of hydroxycinnamic acids in the studied chia seeds was performed using the method of spectrophotometry (SP), which is described in the monograph SPhU 2.0 T.3 Ash leaves [25]. UV-1800 Shimadzu spectrophotometer was used. The measurements were performed at a wavelength 
of $525 \mathrm{~nm}$. The content of the sum of hydroxycinnamic acids was calculated as a percentage, based on chlorogenic acid [26].

Determination of the swelling index was performed according to the method of SPhU [19].

The content of polysaccharides in raw materials was determined by gravimetric method according to the method described in the monograph SPhU 2.0 T.3 Althaea roots [25].

\section{Research results}

Macroscopic examination of Salviae hispanicae semina.

Chia seeds are small, have a flattened, oval shape. Seed skin brown, gray, black or white with a relief pattern, smooth and shiny. Seeds $2 \mathrm{~mm}$ long, $1.3 \mathrm{~mm}$ wide, $0.6 \mathrm{~mm}$ thick; one end is rounded, the other is beveled (Fig. 2). There is a scar on the beveled edge. Beneath the seed coat is a narrow, whitish endosperm and an embryo of two round, flat oily cotyledons.
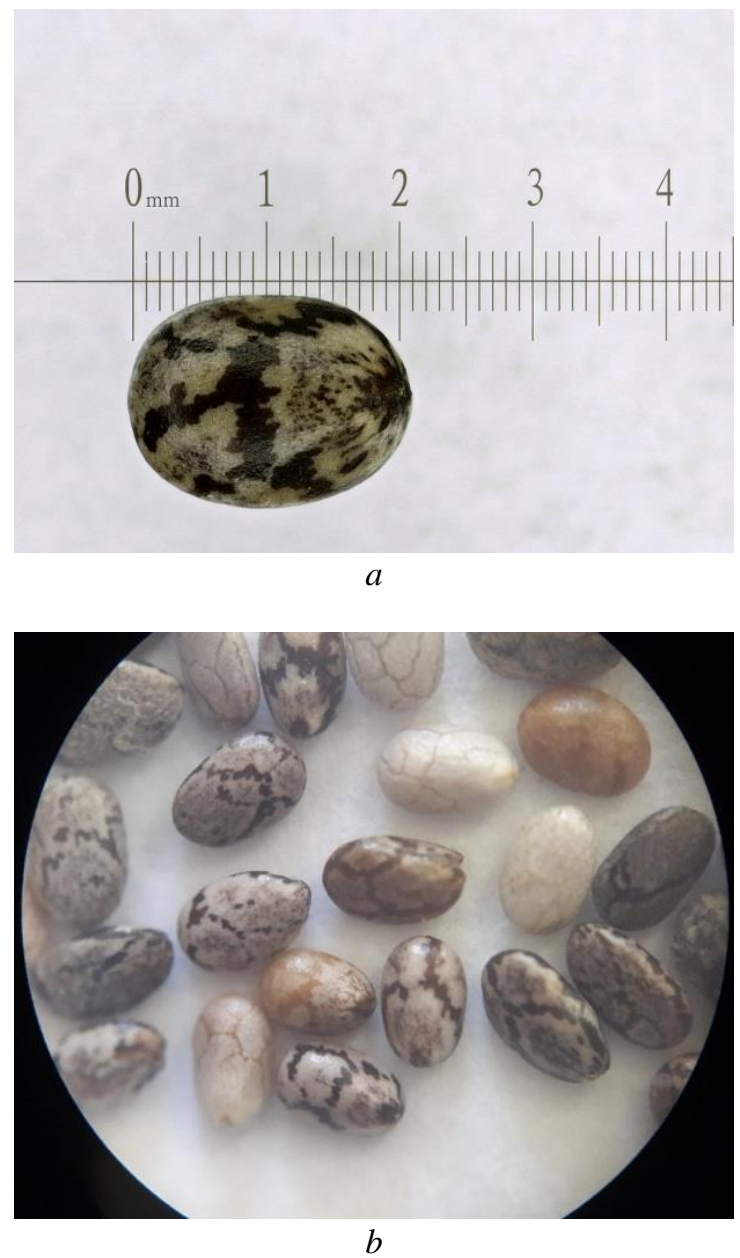

Fig. 2. Appearance of chia seeds: $a-($ magn. $\times 40)$; $b-($ magn. $\times 20)$

Microscopic analysis of Salviae hispanicae semina

The results of the study of chia seeds under a stereomicroscope revealed that the seed coat is shiny, leathery, porous, with a relief pattern and grooved surface, endosperm - oily, yellowish-white, fleshy (Fig. 3).

As a result of studying chia seeds under a light microscope, we determined: fragments of the endosperm parenchyma with aleurone grains and fatty oil in oleoplasts (Fig. 4); fragments of the epidermis with a wrinkled cuticle; T-similar mucus-containing two-cell hairs on the cross section of the seed and on the whole raw material after the reaction with methylene blue (Fig. 4); fragments of the inner epidermis of the seed coat of cells, polygonal with thickened shells, with drops of fatty oil after reaction with Sudan III (Fig. 4); fragment of the seed scar.

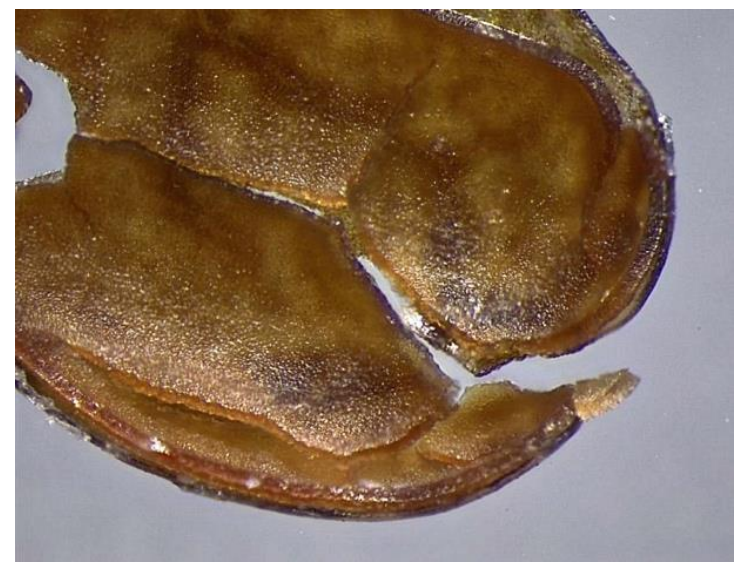

$a$

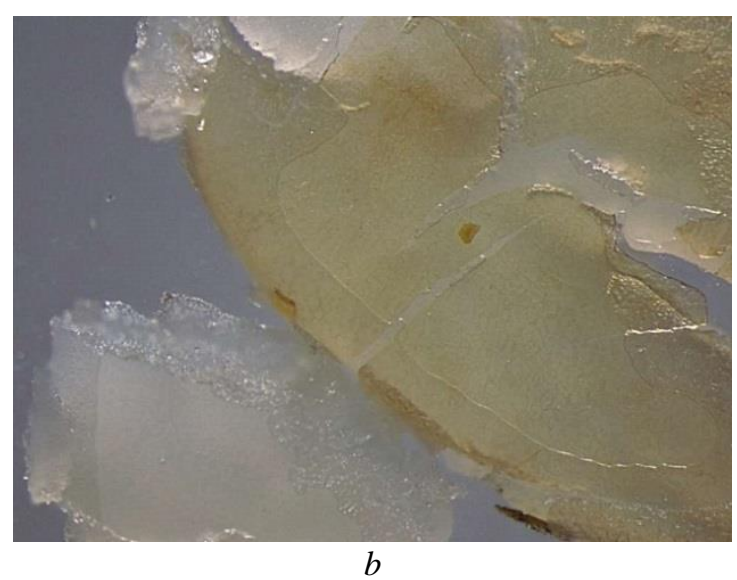

Fig. 3. Chia seeds (magn. $\times 128$ ): $a$ - peel; $b$-endosperm

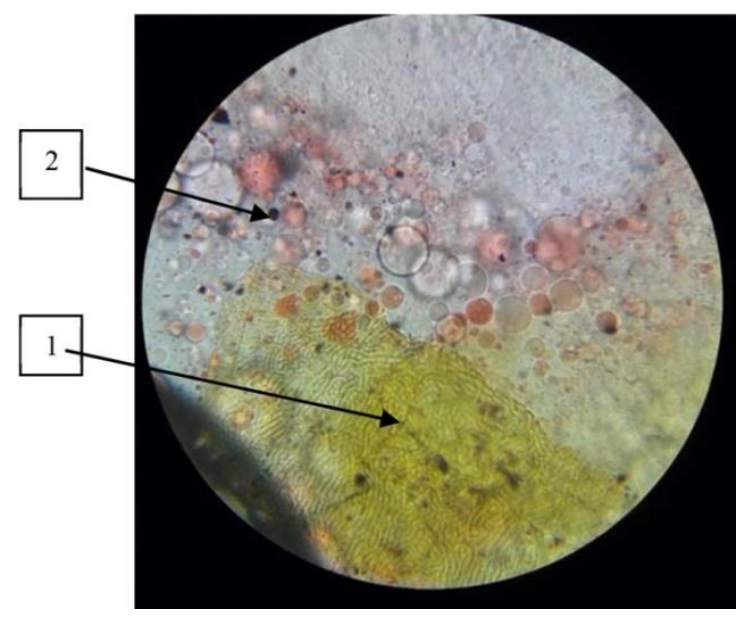

Fig. 4. Fragment of the parenchyma of the endosperm of Spanish sage seeds (magn. $1 \times 100): 1$ - polygonal cells of the epidermis with thickened shells; 2 - drops of fatty oil after reaction with Sudan III 


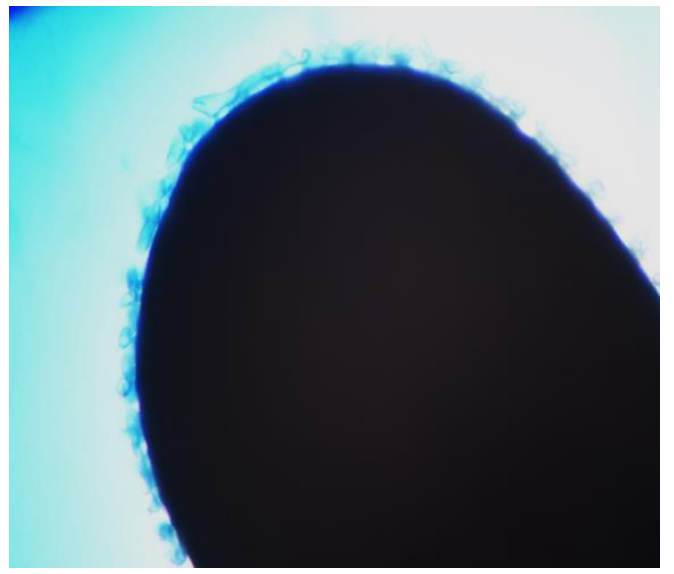

Fig. 5. T-shaped mucous two-cell hairs on the whole raw material after reaction with methylene blue (1:5000)

(magn. 1×40).

\section{Histochemical reactions}

The complex of researches allowed to establish the presence of mucus and fatty oils in the studied MPRM (Figs. 4, 5).

Chemical reactions

The presence of flavonoids in the raw material was established by qualitative analysis. All qualitative reactions that were carried out to identify them gave a positive result, except for the cyanidin reaction and the reaction with aluminium chloride [20].

The analysis shows the absence of saponins, tannins and alkaloids in chia seeds.

Identification of hydroxycinnamic acids

The PC method (solvent system: $15 \%$ acetic acid solution) in the alcoholic extract of chia seeds revealed chlorogenic acid, which in UV light appeared green-blue color after treatment with ammonia vapor.

Quantitative content of fatty acids

The yield of lipophilic extract of chia seeds was $24.0 \pm 4.2 \%$. When determining the quantitative content of fatty acids of the obtained lipophilic fraction, the experimental data showed a difference from the literature (Table1).

Table 1

Quantitative content of fatty acids in the chia seeds

\begin{tabular}{|l|l|c|}
\hline Index & \multicolumn{1}{|c|}{ FA } & $\begin{array}{c}\text { The content } \\
\text { of fatty acids, } \%\end{array}$ \\
\hline $\mathrm{C}_{14: 0}$ & Myristic acid & $0.3 \pm 0.01$ \\
\hline $\mathrm{C}_{15: 0}$ & Pentadecanoic acid & $0.3 \pm 0.01$ \\
\hline $\mathrm{C}_{16: 0}$ & Palmitic acid & $8.7 \pm 0.36$ \\
\hline $\mathrm{C}_{17: 0}$ & Margaric acid & $0.3 \pm 0.01$ \\
\hline $\mathrm{C}_{18: 0}$ & Stearic acid & $2.3 \pm 0.08$ \\
\hline $\mathrm{C}_{18: 1}$ & Oleic acid & $9.5 \pm 0.38$ \\
\hline $\mathrm{C}_{18: 2}$ & Linoleic acid & $78.0 \pm 3.04$ \\
\hline $\mathrm{C}_{18: 3}$ & Linolenic acid & $0.3 \pm 0.01$ \\
\hline $\mathrm{C}_{20: 4}$ & Arachidonic acid & $0.3 \pm 0.01$ \\
\hline$\sum$ saturated FA & 11.9 \\
\hline$\Sigma$ unsaturated FA & 88.1 \\
\hline$\Sigma$ poli unsaturated FA & 78.6 \\
\hline
\end{tabular}

The obtained experimental data show that linoleic acid (78.0\% of the total fat content) predominates in the samples we study in terms of quantitative content, and its content is $17-22 \%$ in terms of literature data. The content of linolenic acid, on the contrary, prevails according to the literature (56-65\%), and in our samples it is almost absent $(0.3 \%)$ [27].

\section{Swelling index}

According to SPhU, one of the indicators of the quality of raw materials containing mucus is the swelling index [19]. The swelling index is the volume in $\mathrm{ml}$, which occupies $1 \mathrm{~g}$ of medicinal plant material after its swelling in an aqueous medium for 4 hours, including sticky mucus.

As a result of determining the swelling index, it was found that this indicator for whole chia seeds was 20 , and crushed -17 , which indicates a significant content of mucus in the studied raw materials.

Quantitative content of polysaccharides

As a result of research of polysaccharide compounds in raw materials by gravimetric method it was found that the content of water-soluble polysaccharides in whole raw materials is $4.01 \pm 0.07 \%$, and when using crushed raw materials $-5.04 \pm 0.05 \%$.

Quantitative content of hydroxycinnamic acids

The content of hydroxycinnamic acids in the chia seeds was $1.07 \pm 0.03 \%$.

\section{Discussion of research results}

Macro- and microscopic, histochemical studies of chia seeds revealed its specific anatomical and morphological features that are important for the diagnosis of MPRM: seeds are small, oval, one end is rounded, the other is bevelled, the skin with a relief pattern, smooth, shiny, has T-like mucus-containing two-celled hairs, which retain mucus after swelling; the inner epidermis of the seminal vesicle consists of polygonal cells with thickened shells; endosperm parenchyma with wrinkled cuticle, with aleurone grains and fatty oil in oleoplasts. The conducted researches give the chance to identify the whole and powdered plant raw materials, and also to differentiate it with possible impurity.

The results of phytochemical and histochemical studies of whole and powdered MPRM revealed the presence of mucus, fatty oils, water-soluble polysaccharides, flavonoids, hydroxycinnamic acids and confirmed the absence of chia saponins, tannins and alkaloids in the seeds.

Chemical reactions to flavonoids indicate the absence of oxidized phenylchroman derivatives in the raw material and the presence of reduced phenylchroman derivatives - halocatechins (positive reaction with a solution of vanillin in sulfuric acid and negative reaction with aluminium (III) chloride) [20]. It is known from the literature that chia seeds contain kaempferol and quercetin, but the content of these substances is not significant, which is confirmed by studies [27].

It was found that grinding affects the yield of mucus and polysaccharides of chia raw materials: the swelling index for whole chia seeds was 20 , and crushed -17 ; the content of water-soluble polysaccharides in the whole raw material is $4.01 \pm 0.07 \%$, and in the crushed $5.04 \pm 0.05 \%$.

According to HFCs, the swelling index of branched plantain seeds is not less than 10, and for flax seeds - not less than 4 [25]. According to the results of our research, the index of swelling of chia seeds is 
2 times higher than the index of swelling of branched plantain seeds and 5 times higher than that of flax seeds. This indicates the viability of using chia seeds as a source of mucus.

Given the important role of polysaccharides in the functioning of organs and systems in the body and in pathology (lipid metabolism, normalization of intestinal microbiota, detoxification processes), the studied MPRM can be considered as an important source of BAS [28]. The obtained results on the content of mucus and polysaccharides confirm the studies of other authors [17, 20] and indicate the possibility of using chia seeds as MPRM with enveloping, mild laxative and anti-inflammatory action in diseases of the gastrointestinal tract.

The presence of hydroxycinnamic acids makes it possible to predict the antioxidant, immunomodulatory, hepatoprotective, etc. effects of chia seeds [29].

The experimental data obtained in the study of the fatty acid composition of chia seeds show an advantage in the quantitative content of linoleic acid $(78.0 \pm 3.04 \%)$, which differs from the literature data, according to which in the studied MPRM quantitative content is dominated by linolenic acid (56-65\%) [27]. This may be due to the long transportation and storage of raw materials, which does not change the total amount of unsaturated fatty acids, but affects its quality composition. The fatty oil of the studied chia seeds can be attributed to semidrying fatty oils, as it is dominated by glycerides of linoleic acid.

Study limitations. The obtained results could be used to state that the chia seeds may have a wide range of pharmacological action, but do not confirm these assumptions.

Prospects for further research. Further research can be aimed at establishing different types of pharmacological activity of chia seeds: anti-inflammatory, laxative, antioxidant, hepatoprotective and others.

\section{Conclusions}

1. A comprehensive macro- and microscopic, histochemical and phytochemical study of chia seeds was performed.

2. Confirmed the presence of chia seeds in the composition of mucus, fatty oils, water-soluble polysaccharides, flavonoids, hydroxycinnamic acids.

3 . The swelling index for whole seeds is -20 , and crushed -17 . The content of water-soluble polysaccharides in the whole raw material is $4.01 \pm 0.07 \%$, and in the crushed $-5.04 \pm 0.05 \%$.

4. The quantitative content of hydroxycinnamic acids $(1.07 \pm 0.03 \%)$ was established.

5 . The quantitative content of fatty oils $(24.0 \pm 1.2 \%)$ was determined. 9 fatty acids in chia seeds with a predominant quantitative content of linoleic acid $(78.0 \pm 3.04 \%)$ were identified by GC method.

6 . The obtained results can be used as a basis for the development of quality control methods for chia seeds for further use of this raw material in medicine and pharmacy.

\section{Conflict of interests}

The authors declare that they have no conflicts of interest.

\section{References}

1. Sofer, S., Stark, A. H., Madar, Z. (2015). Nutrition Targeting by Food Timing: Time-Related Dietary Approaches to Combat Obesity and Metabolic Syndrome. Advances in Nutrition, 6 (2), 214-223. doi: http://doi.org/10.3945/an.114.007518

2. Ayerza, R., Coates, W., Lauria, M. (2002). Chia seed (Salvia hispanica L.) as an omega-3 fatty acid source for broilers: influence on fatty acid composition, cholesterol and fat content of white and dark meats, growth performance, and sensory characteristics. Poultry Science, 81 (6), 826-837. doi: http://doi.org/10.1093/ps/81.6.826

3. Ullah, R., Nadeem, M., Khalique, A., Imran, M., Mehmood, S., Javid, A., Hussain, J. (2015). Nutritional and therapeutic perspectives of Chia (Salvia hispanica L.): a review. Journal of Food Science and Technology, 53 (4), 1750-1758. doi: http://doi.org/ 10.1007/s13197-015-1967-0

4. Ayaz, A., Akyol, A., Inan-Eroglu, E., Kabasakal Cetin, A., Samur, G., Akbiyik, F. (2017). Chia seed (Salvia Hispanica L.) added yogurt reduces short-term food intake and increases satiety: randomised controlled trial. Nutrition Research and Practice, 11 (5), 412-418. doi: http://doi.org/10.4162/nrp.2017.11.5.412

5. Attalla, N. R., El-Hussieny, E. A. (2017). Characteristics of Nutraceutical Yoghurt Mousse Fortified with Chia Seeds. International Journal of Environment, Agriculture and Biotechnology, 2 (4), 2033-2046. doi: http://doi.org/10.22161/ijeab/2.4.61

6. Derewiaka, D., Stepnowska, N., Bryś, J., Ziarno, M., Ciecierska, M., Kowalska, J. (2019). Chia seed oil as an additive to yogurt. Grasas y Aceites, 70 (2), 302. doi: http://doi.org/10.3989/gya.0705182

7. COMMISSION DECISIONof 13 October 2009 authorising the placing on the market of Chia seed (Salvia hispanica) as novel food ingredient under Regulation (EC) No 258/97 of the European Parliament and of the Council (2009). Official Journal of the European Union. Available at: https://eur-lex.europa.eu/LexUriServ/LexUriServ.do?uri=OJ:L:2009:294:0014:0015:EN:PDF

8. Da Silva, B. P., Anunciação, P. C., Matyelka, J. C. da S., Della Lucia, C. M., Martino, H. S. D., Pinheiro-Sant'Ana, H. M. (2017). Chemical composition of Brazilian chia seeds grown in different places. Food Chemistry, 221, 1709-1716. doi: http://doi.org/10.1016/ j.foodchem.2016.10.115

9. Application for the authorization of chia seed from Salvia hispanica L. for consumption as a food and as an ingredient in additional food groups (2011). Available at: https://acnfp.food.gov.uk/sites/default/files/mnt/drupal_data/ sources/files/multimedia/ pdfs/applicdosschiacompany.pdf

10. De Souza Ferreira, C., de Sousa Fomes, L. de F., da Silva, G. E. S., Rosa, G. (2015). Effect of chia seed (Salvia hispanica L.) consumption on cardiovascular risk factors in humans: a systematic review. Nutricion hospitalaria, 32, 1909-1918. doi: http://doi.org/ 10.3305/nh.2015.32.5.9394

11. Jeong, S. K., Park, H. J., Park, B. D., Kim, I.-H. (2010). Effectiveness of Topical Chia Seed Oil on Pruritus of End-stage Renal Disease (ESRD) Patients and Healthy Volunteers. Annals of Dermatology, 22 (2), 143-148. doi: http://doi.org/10.5021/ad.2010.22.2.143

12. Nieman, D. C., Gillitt, N., Jin, F., Henson, D. A., Kennerly, K., Shanely, R. A. et. al. (2012). Chia Seed Supplementation and Disease Risk Factors in Overweight Women: A Metabolomics Investigation. The Journal of Alternative and Complementary Medicine, 18 (7), 700-708. doi: http://doi.org/10.1089/acm.2011.0443 
13. Park B. D., Jung S. G., Park H. J. (2010). Pat. No. 2010005799 Korea. Skin external composition containing chia seed oil.

14. Marineli, R. da S., Lenquiste, S. A., Moraes, É. A., Maróstica, M. R. (2015). Antioxidant potential of dietary chia seed and oil (Salvia hispanica L.) in diet-induced obese rats. Food Research International, 76, 666-674. doi: http://doi.org/10.1016/j.foodres.2015.07.039

15. Mohd Ali, N., Yeap, S. K., Ho, W. Y., Beh, B. K., Tan, S. W., Tan, S. G. (2012). The Promising Future of Chia, Salvia hispanicaL. Journal of Biomedicine and Biotechnology, 2012, 1-9. doi: http://doi.org/10.1155/2012/171956

16. Fortino, M. A., Oliva, M. E., Rodriguez, S., Lombardo, Y. B., Chicco, A. (2017). Could post-weaning dietary chia seed mitigate the development of dyslipidemia, liver steatosis and altered glucose homeostasis in offspring exposed to a sucrose-rich diet from utero to adulthood? Prostaglandins, Leukotrienes and Essential Fatty Acids, 116, 19-26. doi: http://doi.org/10.1016/j.plefa.2016.11.003

17. Kulczyński, B., Kobus-Cisowska, J., Taczanowski, M., Kmiecik, D., \& Gramza-Michałowska, A. (2019). The Chemical Composition and Nutritional Value of Chia Seeds - Current State of Knowledge. Nutrients, 11 (6), 1242. doi: http://doi.org/10.3390/nu11061242

18. Villanueva-Bermejo, D., Calvo, M. V., Castro-Gómez, P., Fornari, T., Fontecha, J. (2019). Production of omega 3-rich oils from underutilized chia seeds. Comparison between supercritical fluid and pressurized liquid extraction methods. Food Research International, 115, 400-407. doi: http://doi.org/10.1016/j.foodres.2018.10.085

19. Derzhavna Farmakopeia Ukrainy. Vol. 1. (2015). Kharkiv: Derzhavne pidpryiemstvo «Ukrainskyi naukovyi farmakopeinyi tsentr yakosti likarskykh zasobiv», 1128.

20. Souza, D. M. F. D., Sá, R. D., Araújo, E. L., Randau, K. P. (2018). Anatomical, phytochemical and histochemical study of Solidago chilensis Meyen. Anais Da Academia Brasileira de Ciências, 90 (2 suppl 1), 2107-2120. doi: http://doi.org/10.1590/ 0001-3765201720160280

21. Koshevoi, O. N. (2011). Amino-acid and monosaccharide compositions of Salvia officinalis leaves. Chemistry of Natural Compounds, 47 (3), 492-493. doi: http://doi.org/10.1007/s10600-011-9976-3

22. Koshovyi O, Raal A, Kovaleva A, Myha M, Ilina T, Borodina N, Komissarenko A. (2020). The phytochemical and chemotaxonomic study of Salvia spp. growing in Ukraine. Journal of Applied Biology \& Biotechnology, 8 (3), 29-36. doi: http://doi.org/10.7324/ jabb.2020.80306

23. Karpiuk, U. V., Abudayeh, Z. H. M., Kyslychenko, V. S., Yemelianova, O. I. (2017). Isolation and Identification of some Primary Metabolites, Micro- and Macroelements of Aesculus hippocastanum L. Seeds. International Journal of Pharmacognosy and Phytochemical Research, 9 (1), 108-113. doi: http://doi.org/10.25258/ijpapr.v9i1.8049

24. Karpiuk, U. V., Omelchenko, Z. I., Kislichenko, V. S. (2009). Chromatographic detection and identification of lipophylic compounds of Glycine and Setaria genus. Herba polonica, 55 (1), 43-52.

25. Derzhavna Farmakopeia Ukrainy. Vol. 3 (2014). Kharkiv: Derzhavne pidpryiemstvo «Ukrainskyi naukovyi farmakopeinyi tsentr yakosti likarskykh zasobiv», 732.

26. Starchenko, G., Hrytsyk, A., Raal, A., Koshovyi, O. (2020). Phytochemical Profile and Pharmacological Activities of Water and Hydroethanolic Dry Extracts of Calluna vulgaris (L.) Hull. Herb. Plants, 9 (6), 751. doi: http://doi.org/10.3390/plants9060751

27. Ikumi, P., Mburu, M., Njoroge, D. (2019). Chia (Salvia hispanica L.) - A Potential Crop for Food and Nutrition Security in Africa. Journal of Food Research, 8 (6), 104-118. doi: http://doi.org/10.5539/jfr.v8n6p104

28. Liu, J., Willför, S., Xu, C. (2015). A review of bioactive plant polysaccharides: Biological activities, functionalization, and biomedical applications. Bioactive Carbohydrates and Dietary Fibre, 5 (1), 31-61. doi: http://doi.org/10.1016/j.bcdf.2014.12.001

29. Sova, M., Saso, L. (2020). Natural Sources, Pharmacokinetics, Biological Activities and Health Benefits of Hydroxycinnamic Acids and Their Metabolites. Nutrients, 12 (8), 2190. doi: http://doi.org/10.3390/nu12082190

Received date 15.03.2021

Accepted date 20.04.2021

Published date 30.04.2021

Anastasiia Sytryn, Pharmacist-specialist, GMBH "Nextpharm", V. Gavela blvd., 40A, Kyiv, Ukraine, 03126 E-mail: tereshkina.anastasia@gmail.com

Iryna Cholak, PhD, Department of Pharmacognosy and Botany, Bogomolets National Medical University, T. Shevchenka blvd., 13, Kyiv, Ukraine, 01601

E-mail: sophora9@gmail.com

Oksana Yemelianova, PhD, Associate Professor, Department of Pharmacognosy and Botany, Bogomolets National Medical University, T. Shevchenka blvd., 13, Kyiv, Ukraine, 01601

E-mail: oxanay11@gmail.com

Uliana Karpiuk, Doctor of Pharmaceutical Sciences, Associate Professor, Department of Pharmacognosy and Botany, Bogomolets National Medical University, T. Shevchenka blvd., 13, Kyiv, Ukraine, 01601

E-mail: uliana.karpiuk@gmail.com 